\title{
The perils of poultry
}

Published at www.cmaj.ca on Jun. 17.

A larming new data from the Public Health Agency of Canada suggests that widespread offlabel use of cephalosporin antibiotics in poultry hatcheries is triggering human resistance to the class of antibiotics.

Experts say the data warrants restrictions on off-label (use of drugs for unapproved clinical indications, also known as extra-label) farm use of cephalosporins in the interest of public health.

Health Canada's response to date has been the introduction of nonbinding labels warning against off-label cephalosporin use in agriculture - a measure that critics say has had little effect on usage levels.

Although the department promised the European Commission almost a decade ago that it would tighten controls on off-label use of drugs in agriculture, and acknowledges that it could ban the sale of cephalosporins for use in all or some food animals, it contends that jurisdiction over farm use of the antibiotics falls within the purview of the provinces. Health Canada, a spokesman says, "does not have authority over extra-label drug use."

Critics counter that the government is simply dodging action on a growing public health problem and should obligate meat and poultry producers to curb antibiotic use and modify practices that stress animal health.

Much of the debate surrounds surveillance data from the Canadian Integrated Program for Antimicrobial Resistance (CIPARS), which strongly indicates that cephalosporin resistance in humans is moving in lockstep with use of the drug in poultry production.

Financed by a \$3-million annual contribution from the Public Health Agency of Canada, CIPARS has been tracking antimicrobial-resistant bacteria in food and on farms since 2002. In 2005, it reported startling levels of cephalosporinresistant bacteria in chicken samples purchased in grocery stores in Quebec

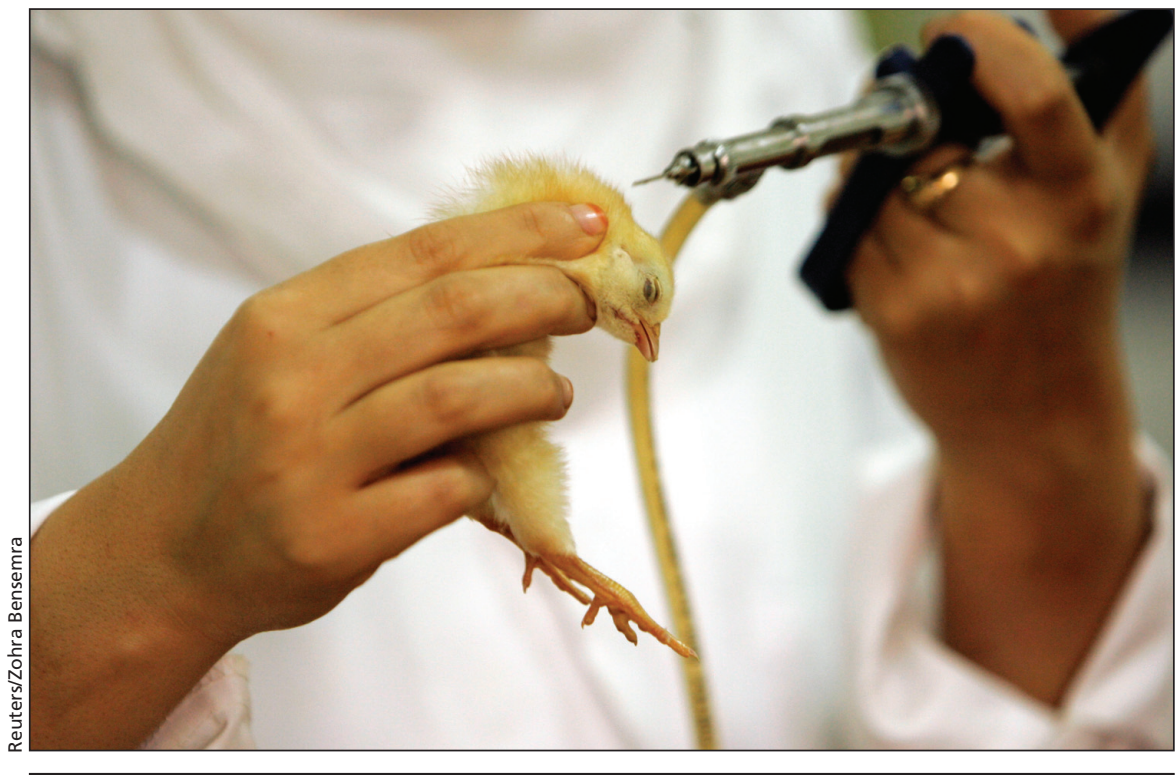

Cephalosporin antibiotics are routinely injected in chicks as a prophylactic.

and Ontario and in samples taken from humans (www.phac-aspc.gc.ca/ciparspicra/2005-eng.php). At the same time, a study revealed near-universal use of ceftiofur, a cephalosporin-type antibiotic, in Quebec chicken hatcheries.

The resistance levels in Quebec were so high that hatcheries voluntarily agreed to temporarily suspend ceftiofur use. CIPARS director Rebecca Irwin says the temporary ban led to a rapid reduction in cephalosporin resistance in salmonella samples taken from humans as well as from retail chicken products.

But more than 2 years after the voluntary ban was lifted, the latest data on poultry products purchased in the province indicate that resistance in salmonella bacteria is again rising, Irwin told researchers at a May conference at the University of Guelph, in Guelph, Ontario. "We are seeing an animal connection that we never saw before."

In fact, CIPARS has issued 4 annual reports since 2005 that reinforce the suspicion that ceftiofur use in chicken hatcheries is helping drive resistance to cephalosporins. Such resistance is "becoming a communitywide problem in Canadian cities," says Johann Pitout, a medical microbiologist with Calgary Laboratory Services in Calgary, Alberta.

A CIPARS update released in March indicated that ceftiofur resistance in bacteria in chicken and in humans rose dramatically in Ontario in 2008, (www .phac-aspc.gc.ca/cipars-picra/heidelberg /heidelberg_090326-eng.php).

Specialists on antimicrobial resistance say that the cumulative evidence is overwhelming and that the time has come to protect one of the most valuable classes of antibiotics used to treat tough-to-beat human infections.

"The CIPARS data are the most convincing I have ever seen," says Frank Aarestrup, a specialist on antibiotic resistance with the Danish Technical University in Copenhagen who helped introduce a system of comprehensive surveillance of all veterinary drug use in Denmark since 2000.

Researchers have been intensively probing links between antibiotics in agriculture and antibiotic resistance in humans for well over a decade, Aarestrup says.

CIPARS has settled the issue, he adds. "Taken in context with all the 
other knowledge we have, anyone still opposing a link between antibiotic use in food animal production and direct human health impact does so for other reasons than science."

James Johnson, an infectious disease specialist with the Veterans Administration Medical Center in Minneapolis, Minnesota, concurs. "In the world of observational studies, the CIPARS effort is as good as it gets.'

The CIPARS studies focused in part on ceftiofur, a third-generation cephalosporin antibiotic marketed by Pfizer Canada Inc. for use in turkey, cattle, swine, lambs, dogs and horses. It has not been approved for use in chicken or eggs but is often robotically injected - on an off-label basis — into eggs as a prophylactic. It prevents potentially costly infection outbreaks in chickens, explains Daniel Venne, a veterinarian with Quebec hatchery operator Couvoir Scott Ltee.

Venne and other veterinarians caution that the CIPARS data do not conclusively prove a link between their use of ceftiofur and the parallel emergence of cephalosporin-resistant pathogens in humans.

Other experts, though, argue that the data warrant the introduction of stricter federal regulations. "The CIPARS data appears to be answering the question about a linkage between usage of antibiotics in animals and human resistance," says Jim Hutchinson, chair of the Canadian Committee of Antimicrobial Resistance.

In the United States, a review of the CIPARS data helped lead the Food and Drug Administration (FDA) to propose a ban in July 2008 on the off-label use of cephalosporins (http://edocket.access .gpo.gov/2008/E8-15052.html).

But after meat and poultry industry associations fought back, the FDA retracted the proposal in favour of further consultations. "The FDA has revoked the order prohibiting the extra-label use of cephalosporins to allow our scientists the time necessary to consider substantive public comments," explains agency spokeswoman Laura Alvey.

The CIPARS data helped fuel an intense political fight in Washington, D.C., says Morgan Scott, an epidemiologist at Kansas State University in
Manhattan, Kansas. "A lot of us were blown away by what we saw in the CIPARS data," says Scott, adding that the FDA recently signalled its intention to reintroduce regulations limiting cephalosporin usage in agriculture.

Aaerstrup says Canadian management of veterinary use of antibiotics is less stringent than in many European countries. He notes that as early as 2003, a Danish supermarket chain rejected quail meat contaminated with salmonella resistant to cephalosporins, "as a food safety precaution."

By contrast, in Canada, it appears that industry concerns trump precautionary principles.

Jérôme Castillo, a University of Montréal veterinarian who serves on CIPARS' scientific advisory board, says that chicken hatcheries began using ceftiofur due to difficulties obtaining drugs capable of containing disease outbreaks.

A single injection of ceftiofur into eggs "proved quite effective," he explains. But the subsequent appearance of cephalosporin resistance in chickens was also pronounced, he adds.

Nevertheless, Castillo warns that the "causal relationship between what the poultry veterinarians did and what appeared in the human laboratories is something that has to be taken with caution. It's not something that is necessarily cause and effect."

Some of the uncertainty about the link appears to stem from an inability to collect data that might confirm the case. Irwin has frequently complained of trouble accessing drug-usage data in many provinces because of commercial barriers. "People can hide behind whatever," she told researchers at the Guelph gathering in May. "We're still getting the 'hear no evil, see no evil, speak no evil' from numerous sources."

Steve Leech, national program manager of the Chicken Farmers of Canada, explains that although antibiotic-usage data from chicken flocks is submitted to inspectors with the Canadian Food Inspection Agency, CIPARS does not have access to the data because both industry and the inspection agency consider it confidential business information. But Leech says the chicken industry is working now with CIPARS to improve on-farm surveillance of an-

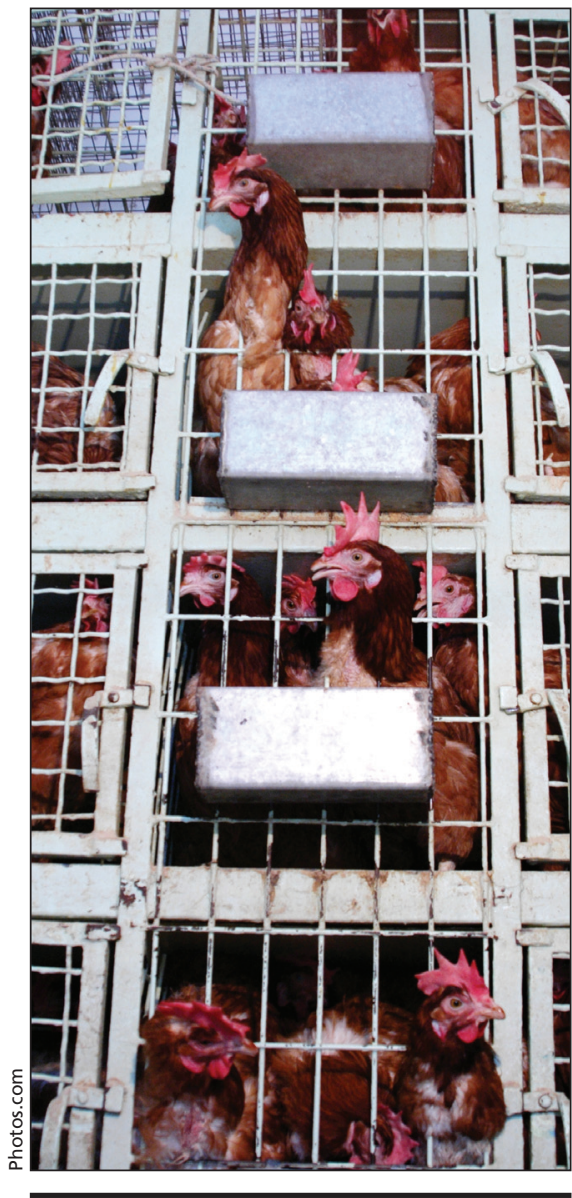

The most recent CIPARS update indicates that antibiotic resistance in retail chicken bacteria increased in Quebec, Ontario, British Columbia and Saskatchewan from 2007 to 2008.

tibiotic use and resistance. "It comes down to finalizing the protocol and securing the financing."

What national data that now exist on ceftiofur usage is based on information collected by hatcheries, confirms Rachel Ouckama, a veterinarian with Maple Lodge Farms in Port Hope, Ontario.

A glimpse into usage was provided to CIPARS in May at a closed meeting organized by the Public Health Agency of Canada and Health Canada, at which, Ouckama says, indications were given that ceftiofur is routinely injected into eggs in hatcheries in Ontario, Quebec and the rest of country. The Public Health Agency of Canada wants the "poultry industry to better define antimicrobial use to facilitate interpretation of our CIPARS data."

Meanwhile, resistance continues to rise. In late March, CIPARS released 
an update indicating that from 2007 to 2008 , resistance in retail chicken bacteria increased in Quebec, Ontario, British Columbia and Saskatchewan with $\mathrm{BC}$ posting the highest gain from $29 \%$ to $46 \%$.

"The rates of resistance are certainly alarming," says University of British Columbia Faculty of Medicine infectious disease specialist Bill Bowie. "Since ceftiofur resistance likely correlates with resistance to drugs like ceftriaxone, and similar cephalosporins in use in human medicine, this resistance in poultry predicts that proportions of the human population are being exposed to the resistance factors."

Further concern was expressed in December 2008 by Ontario's Auditor General, who reported that "no corrective action" was taken in response to a provincial antibiotic residue-testing project that indicated "a high number of adverse results" for a number of animal classes (www.auditor.on.ca/en/reports _en/en08/309en08.pdf).

Some members of industry have also expressed concern. At a 2005 conference, Bill Ballantyne, technical director for procurement with Maple Leaf Foods, which operates 2 Ontario hatcheries and markets Canada's leading brand of chicken, indicated that the "uncertainties" of antimicrobial resistance "represent a significant risk for the meat industry." Ballantyne added that the industry was "confused by the apparent inability to separate political, economic and scientific agendas on farm safety programs."

Maple Leaf, though, declined requests to interview Ballantyne or a company veterinarian about ceftiofur usage. "Our veterinarians administer antibiotics in the hatcheries when they are needed," spokesperson Rachel Douglas stated in an email. "We source from a list of federally approved antibiotics for limited use in our hatcheries."

Although Health Canada says it does not have up-to-date information about such off-label usage, a 1990 survey commissioned by the department found that 260 of 310 veterinarians employed off-label use of veterinary drugs, either to species not indicated on the label, or at higher dosages than recommended (www.hc-sc.gc.ca/dhp-mps /pubs/vet/eldu-umdde_issue-enjeux_final _10-12-2004-eng.php).

The extent of off-label use has already had trade implications. In 2000, a team of European Commission trade inspectors concluded that Canadian meat products did not meet European safety standards largely because of "inadequate restrictions" on off-label usage.

European Union inspectors found numerous safety violations and noted that approximately 50 veterinary drugs — including a carcinogen banned in Europe and antibiotics banned for their role in the development of resistant bacteria - "are freely available for farmers and feedlot operators as medicating ingredients authorized for incorporation in livestock feedingstuffs." The investigators also noted that many drugs were administered directly by farm workers without veterinary supervision (ec.europa.eu/food/fs/inspections/vi /reports/canada/vi_rep_cana_1188-2000 _en.pdf).

In response, Ottawa promised the European Commission that it would enhance control of off-label drug use "through the combined force and impact of federal and provincial legal and regulatory frameworks." The government launched a national study, which was eventually abandoned.

Similarly, in 2002, Health Canada was advised by its Advisory Committee on Animal Uses of Antimicrobials and Impact on Resistance and Human Health to develop a more restrictive off-label farm-use policy.

The government responded by appointing a committee to study the issue in 2004. It warned that farmers were importing "unapproved products" for off-label use. Unregulated off-label use was even allowing farmers to "compound" or make their drug mixes, a practice that "may involve human drugs, approved or unapproved drug products" (www.hc-sc.gc.ca/dhp$\mathrm{mps} / \mathrm{pubs} / \mathrm{vet} / \mathrm{eldu}$-umdde_issue-enjeux _final_10-12-2004-eng.php).

In 2008, the Canadian Veterinary Medical Association issued guidelines stating that ceftiofur should only be used in chickens and eggs in emergency situations.

Eventually, Health Canada took action, adopting a nonbinding and unen- 
forceable policy in 2008 that required a safety warning advising against offlabel usage to be added to ceftiofur packages.

"Based on the available scientific data, including results from CIPARS," department spokesman Stéphane Shank explains, Health Canada "concluded that certain uses of ceftiofur in certain food producing animals have increased the potential for antimicrobial resistance."

Hutchinson calls the new label warning a tepid response. "In the scale of possible regulatory actions, a label change is a very soft step. I don't think a label change is enough."

Hatchery veterinarians in Quebec, Ontario, Alberta and BC confirm that routine off-label usage of ceftiofur now continues in nonemergency situations.

Even so, Shank defends his department's response. "The practice of medicine including veterinary medicine, and hence the use of drugs, is under the authority of the provinces," he says. "Therefore, Health Canada does not have authority over extra-label drug use."

But in the event a drug is found to raise safety issues - which Health Canada acknowledges is why warnings against off-label usage were added to ceftiofur packages — Shank confirms that "Health Canada could introduce regulations to ban the sale of certain drugs for use in food animals and prohibit the sale of animals treated with these drugs for food. These regulations are enforceable."

With no indication from Health Canada that such restrictions are even being contemplated, Hutchinson laments the inaction. "We've been crying from the rafters that we need a whole lot more oversight of antimicrobials," he says. "Antimicrobial resistance is one of the biggest health problems confronting the planet. There is need for federal oversight on this. But the overriding interest seems not to be in human health. And that is a problem for Canadians." Paul Webster, Toronto, Ont, with files from Aruna Handa, Toronto, Ont.

DOI:10.1503/cmaj.091009

\section{FOR THE RECORD}

\section{CMA Secretary-General}

$\mathrm{T}$ he search may have been nationwide but the solution was in-house as the Canadian Medical Association concluded its hunt for a new secretary-general and chief executive officer by appointing PaulÉmile Cloutier to the position.

Cloutier will set aside his current duties as assistant secretary-general for advocacy, communications and public affairs on Jul. 20 to assume the helm of the association's operational arm.

"I think there's 2 challenges," Cloutier says. "One is to keep the doctors together under one voice, especially in light of some of the major debates that we have within CMA, and debates outside CMA. The next one is to find ways to bring CMA to members and find a value or define what value we bring to PTMAs, the provincialterritorial associations. It's our time to start thinking of how we best respond to their needs."

It's important that CMA always speaks on behalf of its $70000 \mathrm{mem}$ bers, particularly with respect to transformation of the health care system, he says. "You don't want to be perceived out there as being an organization to which there are different camps. You want to speak to everyone, at least from

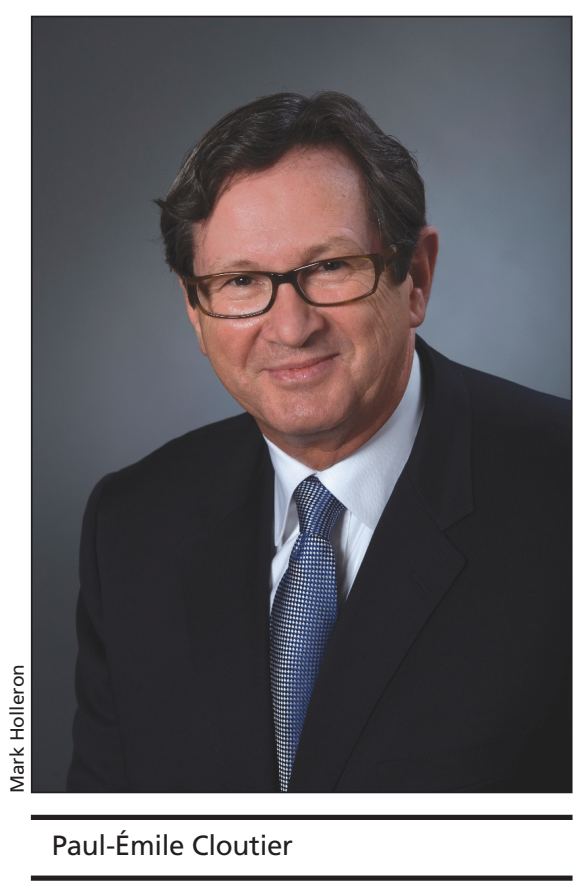

a public point of view, that we are one force."

At their core, all doctors desire "to look at what are some of the better ways of doing the business that they are in, which is patient care."

Among immediate priorities are expanding the membership base; meeting provincial and territorial medical associations to discuss how the national association might better serve their needs; and implementing CMA's new governance structure (CMAJ 2008;179 [6]:520).

If there are extant concerns about governance, "we must find solutions to ensure that none of our divisions, and none of our members, feel disconnect from CMA."

Asked what possessed him to throw his hat in the secretary-general's ring, Cloutier replied that he has a "passion for what we do and I believe in what we do, for both the profession and for patients, for Canadians. ... CMA needs to lead that debate in health care transformation or health care reform and my whole career has been outreach and advocacy and I felt there was something I could bring to the table."

Cloutier joined CMA in 2002 after stints in the Ontario ministry of intergovernmental affairs; the federal departments of Indian affairs, immigration and foreign affairs; and Via Rail Canada.

Cloutier replaces interim secretarygeneral Barbara Drew, who assumed the position when William Tholl resigned after more than 7 years in the job (CMAJ 2008;179[10]:994).

Cloutier is married to Dr. Jocelyne Lalonde, a family physician in Gatineau, Quebec. The couple have a 9-year-old son, Pierre-Alexandre. 